\title{
A PRODUÇÃO CIENTÍFICA BRASILEIRA SOBRE A SUSTENTABILIDADE NO AGRONEGÓCIO: UM RECORTE TEMPORAL ENTRE 2005 E 2015
}

\author{
The Brazilian Scientific Production on Sustainability in the Agribusiness: \\ A Temporal Cut between 2005 and 2015
}

\begin{abstract}
RESUMO
A sustentabilidade constitui um dos temas principais de debates na atualidade. Entende-se como relevante a identificação de como os artigos científicos tèm abordado tal tema. $\mathrm{O}$ objetivo deste artigo, portanto, foi analisar a produção científica brasileira da sustentabilidade no agronegócio com pesquisa de estudos no período de 2005 a 2015 selecionados, na Plataforma Sucupira, nos periódicos nacionais da área de Administração, Ciencias Contábeis e Turismo, com qualificação nos estratos de A1 a B3, pelo sistema de avaliação Qualis Periódicos da Capes (Coordenação de Aperfeiçoamento de Pessoal de Nível Superior), referente ao ano de 2014. O artigo é caracterizado como estudo exploratório, a partir da pesquisa bibliográfica. Desse modo, foram selecionados 47 trabalhos distribuídos em 27 periódicos, com foco no tema central do estudo e apresentando contribuições ao debate. Os resultados apontam que a sustentabilidade no agronegócio em suas diversas atividades e nas mais variadas regiões brasileiras têm crescido nas discussões científicas, bem como percebe-se o desenvolvimento e aplicação de indicadores como principal foco dos trabalhos selecionados. Conclui-se que, apesar do avanço, existem inúmeras lacunas ainda a serem debatidas, pois a insustentabilidade ainda está muito presente no agronegócio nacional, bem como constatou-se a necessidade da adoção de políticas públicas e ações que de fato possibilitem o desenvolvimento sustentável do agronegócio nacional.
\end{abstract}

Tamara Pereira Zanella

Universidade Estadual do Oeste do Paraná

tamarapzanella@hotmail.com

Sandra Mara Stocker Lago

Universidade Estadual do Oeste do Paraná

smstocker@uol.com.br

Recebido em: 03/03/2016. Aprovado em: 17/01/2017.

Avaliado pelo sistema double blind review

Avaliador científico: Daniel Carvalho de Rezende

DOI: 10.21714/2238-68902016v18n4p356

\begin{abstract}
Sustainability is currently one of the main topics of debate. The identification of how the scientific articles has approached this subject is relevant. Therefore, the objective of this article was to analyze the Brazilian scientific production on sustainability in agribusiness using the research of studies from between 2005 to 2015, selected in the sucupira platform in the national journals of Administration, Accounting and Tourism, with qualification in the strata of A1 to B3 by the Qualis Periódicos evaluation system of Capes (Coordination for the Improvement of Higher Level Personnel), regarding the year 2014. The article is characterized as an exploratory study based on bibliographical research. From this, 47 papers distributed in 27 journals were selected, focusing on the central theme of the study and presenting contributions to the debate. The results indicate that sustainability in agribusiness, in its various activities and in the most varied regions of Brazil, has grown in scientific discussions, as well as in the development and application of indicators as the main focus of the selected works. We concluded that, despite the progress, there are many gaps still to be debated, such as the strong absence of sustainability in national agribusiness, as well as the need to adopt public policies and actions that allow for sustainable development of national agribusiness.
\end{abstract}

Palavras-chave: Desenvolvimento Sustentável; Agricultura; Produção Científica; Indicadores.

Keywords: Sustainable Development; Agriculture; Scientific Production; Indicators.

\section{INTRODUÇÃO}

A produção agropecuária nacional tem apresentado grande potencial de evolução, em razão do crescimento do consumo do mercado interno e externo, a riqueza de recursos naturais existentes e as melhorias tecnológicas desenvolvidas. Com isso, o Brasil tem possibilidade de crescer com geração de divisas, a partir do aumento das exportações. Em contrapartida, os países emergentes têm sofrido crescentes exigências de conciliar o crescimento econômico tão desejado com a redução de impactos ambientais (ASSAD; MARTINS; PINTO, 2012).

Para resolver o crescente número de problemas ambientais e sociais flagrados, surgiu um novo conceito denominado sustentabilidade, baseado no tripé: valor econômico, responsabilidade social e ambiental. Entende-se, a partir de então que, para que o desenvolvimento ocorra de fato, faz-se necessária a lucratividade e viabilidade 
econômica, aliado a satisfação do cliente interno e externo das organizações bem como a ecoeficiência no processo produtivo (DIAS, 2011).

O setor do agronegócio apresenta relevante participação na economia nacional. Segundo o Centro de Estudos Avançados em Economia Aplicada da Escola Superior de Agricultura Luiz de Queiroz da Universidade de São Paulo - ESALQ/USP (2015) em 2013, o Produto Interno Bruto (PIB) do agronegócio correspondeu a 22,54\% do PIB total brasileiro. A atividade econômica do agronegócio engloba a integração do setor agrícola e pecuário, desde insumos até os maquinários.

O crescimento econômico nacional e a elevação da representatividade do Brasil, no exterior, foi proporcionada em grande parte pelo agronegócio, já que o país é um dos maiores produtores e exportadores do mundo de commodities agropecuárias (NOVAES et al., 2009).

Contrapondo a importância econômica, o agronegócio também apresenta seu lado negativo, visto que emite anualmente milhões de toneladas de gases poluentes como dióxido de carbono (CO2), metano ( $\mathrm{CH} 4)$, óxido nitroso (N2O), além da poluição dos rios, de solo e o desmatamento gerado (ASSAD; MARTINS; PINTO, 2012).

Conforme relatado, a relevância do tema está no debate crescente sobre a relação entre o aspecto econômico do agronegócio brasileiro e a preocupação com a sustentabilidade dessa atividade econômica.

Visa-se a responder, neste estudo, o seguinte questionamento: como a produção científica brasileira tem abordado o tema da sustentabilidade dentro do agronegócio brasileiro?

Tem-se como objetivo principal: analisar a produção científica brasileira da sustentabilidade no agronegócio com base nos periódicos brasileiros no período de 2005 a 2015 .

O artigo encontra-se assim estruturado: na introdução aborda-se a relevância e atualidade do tema, posteriormente o referencial teórico apresenta conceitos para embasamento relacionados ao tema do artigo. No terceiro item, a metodologia utilizada é descrita para possibilitar replicação de outros estudos. E, por fim, são apresentados os resultados e conclusões obtidas no artigo.

\section{SUSTENTABILIDADE}

A sustentabilidade envolve as dimensões econômica, social e ambiental, conforme termo: The Triple Bottom Line, que envolve três variáveis básicas: people, planet, profit (pessoas, planeta e lucros). Busca-se, portanto, desenvolver o aspecto econômico beneficiando a sociedade e preservando o meio ambiente para gerações futuras a partir do uso consciente dos recursos naturais existentes (ELKINGTON, 2004).

O tripé do desenvolvimento deve ter relevância social, a partir da inclusão, ser sustentado na perspectiva da viabilidade econômica, tudo isso com a adoção de prudência ecológica (SACHS, 2008).

Sustentabilidade é um conceito amplo compreendendo a preservação ambiental, a preocupação com qualidade de vida da sociedade, a competitividade das empresas, a responsabilidade social, o desenvolvimento de tecnologias limpas e a utilização racional dos recursos, entre outros aspectos (SILVA, 2012).

A sociedade vem preocupando-se cada vez mais com a necessidade de buscar alternativas sustentáveis em um mundo com diversos problemas ambientais e sociais. A ideia de desenvolvimento com sustentabilidade parece longe da realidade, no entanto, para torná-lo possível, deve-se entender o desenvolvimento a partir do melhor aproveitamento dos espaços já ocupados, aumentando os níveis de produtividade, sem a necessidade de ocupar novos espaços (BATISTA; ALBUQUERQUE, 2007).

Em geral, a adoção de ações sustentáveis são aplicadas apenas em decorrência de exigências legais, ou por necessidade de certificações (KNEIPP et al., 2012). A adoção de uma política de desenvolvimento sustentável se dá a partir de práticas sustentáveis como a utilização racional dos recursos naturais, a educação nas escolas sobre a sustentabilidade, e avanços tecnológicos e científicos (BATISTA; ALBUQUERQUE, 2007).

Algumas empresas porém, com base nos princípios da sustentabilidade, têm atuado com um caráter estratégico em suas metas mercadológicas e tecnológicas e não de forma reativa. Um exemplo, é o caso da Natura, uma empresa brasileira do setor de cosméticos que utiliza um modelo de negócios que incentiva a sustentabilidade, que Vilha e Carvalho (2005) chamam de "sustentabilidade proativa". Nesse modelo de negócios, a empresa garante na extração das matérias-primas utilizadas a preservação ambiental, e ainda busca o desenvolvimento econômico e social das comunidades de onde são extraídas e manejadas, o que além de melhorar a imagem da empresa, gerando valor para seus acionistas, stakeholders e toda a sociedade transforma os princípios do desenvolvimento sustentável numa oportunidade (VILHA e CARVALHO, 2005).

Existem muitos desafios para a expansão da sustentabilidade, pois são necessárias políticas que maximizem a produtividade dos recursos disponíveis, minimizando 
perdas/desperdícios na cadeia de produção, já que as perdas ou desperdícios elevam os custos produtivos, com consequência também no aspecto ambiental do produto, com possibilidade de impactar na visão da imagem brasileira no mercado global (TORRES et al., 2014).

Constitui-se de fundamental importância o comprometimento com a sustentabilidade em todos os segmentos econômicos. Conforme a natureza produtiva, alguns setores como o agronegócio, possuem desafios maiores (KNEIPP et al., 2012).

\section{AGRONEGÓCIO BRASILEIRO}

O agronegócio é a atividade econômica que envolve a agricultura e pecuária, englobando, desde a produção dos insumos até o consumo do produtos agropecuários. Todo processo envolve etapas como: pesquisa, processamento, comercialização, exportação, entre outras (CONTINI et al., 2006)

O protagonismo constitui o papel do agronegócio na economia brasileira, gerando renda e emprego, e destacando o país no comércio internacional. O Brasil constitui-se o terceiro maior exportador de produtos agrícolas e o primeiro em commodities como: café, açúcar, suco de laranja, álcool, carne de frango e bovina (ASSAD; MARTINS; PINTO, 2012).

Há muito tempo, o agronegócio tem apresentado saldos comerciais positivos, e a balança comercial brasileira é positiva, desde a década passada, em razão da evolução do agronegócio nacional (GAZZONI, 2013). Entre 1999 e 2011, as commodities apresentaram aumento constante em sua participação nas exportações brasileiras, representando participação média de $57,57 \%$. Percebe-se, portanto, a grande relevância das commodities na balança comercial brasileira (SOUZA; VERÍSSIMO, 2013).

Apesar da legislação brasileira ser considerada uma das mais completas do mundo, entende-se que ainda é necessário aprimorar o desenvolvimento de práticas sustentáveis nos diversos setores econômicos do país, dentre eles o agronegócio (GAZZONI, 2013).

\section{SUSTENTABILIDADE NO AGRONEGÓCIO}

A sustentabilidade no setor do agronegócio significa obter produtividade de forma eficiente sem esgotar os recursos naturais existentes. Exige-se, então, desenvolvimento de técnicas que satisfaçam as transformações provenientes da demanda do mercado consumidor, das políticas do governo e tecnologias desenvolvidas (MAIA, 2012).
Destaca-se com frequência cada vez maior a necessidade da sustentabilidade nos mais variados segmentos econômicos, visando a desenvolver-se, de forma sustentável,: proporcionando melhor qualidade de vida para a sociedade, meio ambiente preservado e negócios financeiramente lucrativos (SILVA, 2012).

Tem-se entendido como fundamental o aumento da produção de alimentos, mas, para isso, é necessário elevar os níveis produtivos, com otimização do uso dos recursos, além da melhoria da produtividade do trabalhador, a partir de sua qualificação, e implantação de tecnologias, permitindo o desenvolvimento equilibrado e sustentado do agronegócio (TORRES et al., 2014).

$\mathrm{O}$ agronegócio nacional tem se demonstrado competitivo a nível mundial no decorrer das últimas décadas, devido a diversas conquistas obtidas, dentre elas: aumento expressivo da área de plantio direto, redução do consumo de diesel e de água, devido em grande parte ao desenvolvimento de tecnologias sustentáveis e do crescimento da produtividade. Além disso, muitos fatores garantiram a sustentabilidade do agronegócio: postura empresarial, visão de negócio das diversas cadeias produtivas e políticas públicas, principalmente as macroeconômicas, como as políticas de expansão do crédito e seguro agrícola (GAZZONI, 2013).

Mesmo com todos esses esforços, o agronegócio brasileiro não está livre da concorrência cada vez acirrada do mercado global. Para isso, deve-se superar muitos desafios, buscando a redução do custo de se produzir no Brasil, melhoria na qualidade dos produtos, a partir da certificação e rastreabilidade, faz-se necessário também relação integrada entre as ações do Estado e o atendimento às necessidades dos agentes privados do agronegócio, além de investimento à pesquisa e novas tecnologias (NOVAES et al., 2009).

Diante desse cenário, faz-se necessária a adoção de políticas públicas que permitam o desenvolvimento de alternativas sustentáveis como incentivo a atividades de turismo ecológico e agroecologia para pequenos agricultores, bem como permitir o uso de recursos florestais de forma consciente e o desenvolvimento de tecnologias para melhorar a qualidade de vida (PORTO; MILANEZ, 2009).

\section{METODOLOGIA}

O presente artigo caracteriza-se como estudo exploratório, tendo como forma de pesquisa a bibliográfica, que, de acordo com Gil (2002), constitui pesquisa realizada a partir de material já desenvolvido como artigos científicos,

Organizações Rurais \& Agroindustriais, Lavras, v. 18, n. 4, p. 356-370, 2016 
permitindo ao pesquisador maior abrangência sobre os temas de interesse.

A busca de artigos foi realizada a partir da pesquisa de periódicos, por meio da Plataforma Sucupira disponível no sítio eletrônico da Capes (Coordenação de Aperfeiçoamento de Pessoal de Nível Superior), durante o mês de outubro de 2015.

Inicialmente, foram utilizados periódiocos brasileiros classificados de acordo com o sistema Qualis Periódicos da Capes 2014 nos estratos A1 a B3. Pesquisouse na área de avaliação: Administração, Ciências Contábeis e Turismo. Não havendo periódicos brasileiros no estrato A1, o mesmo foi excluído da pesquisa. Posteriormente, foram selecionados os periódicos com o foco e escopo em administração, agronegócio, sustentabilidade e meio ambiente, devido ao interesse das autoras em ampliar o conhecimento no campo de estudo da sustentabilidade no agronegócio. Os artigos pesquisados são do período de 2005 a 2015, caracterizando uma década de pesquisa no assunto.

Foram obtidas 44 periódicos (conforme Quadro 1) com os temas citados, nos quais pesquisou-se nos campos de busca de cada periódico, no título e resumo um a um a existência de artigos com as seis combinações de termos: sustentabilidade + tecnologia; sustentabilidade + índices; sustentabilidade + agronegócio; sustentabilidade + indicadores; avaliação + sustentabilidade; organizações + sustentabilidade + agronegócio.

QUADRO 1 - Periódicos pesquisados na área de Administração, Ciências Contábeis e Turismo

\begin{tabular}{|c|c|}
\hline Periódicos Pesquisados & Qualis \\
\hline BAR. Brazilian Administration Review & A2 \\
\hline Dados (Rio de Janeiro. Impresso) & A2 \\
\hline RAC. Revista de Administração Contemporânea & $\mathrm{A} 2$ \\
\hline RAE (Impresso)/RAE Eletrônica (Online) & $\mathrm{A} 2$ \\
\hline RAUSP-e (São Paulo) & $\mathrm{A} 2$ \\
\hline Revista Brasileira de Gestão de Negócios (São Paulo. Impresso) & $\mathrm{A} 2$ \\
\hline Revista de Administração (FEA-USP) & $\mathrm{A} 2$ \\
\hline Revista de Administração Pública (Impresso) & $\mathrm{A} 2$ \\
\hline Cadernos EBAPE.BR (FGV) & $\mathrm{A} 2$ \\
\hline Ambiente \& Sociedade (Online)/ Ambiente e Sociedade (Campinas) & $\mathrm{B} 1$ \\
\hline BBR. Brazilian Business Review (Edição em português. Online) & $\mathrm{B} 1$ \\
\hline Economia e Sociedade (UNICAMP. Impresso) & B1 \\
\hline RAM. Revista de Administração Mackenzie & B1 \\
\hline REAd. Revista Eletrônica de Administração (Porto Alegre. Online) & B1 \\
\hline Revista Árvore & B1 \\
\hline Administração Pública e Gestão Social & $\mathrm{B} 2$ \\
\hline Base (São Leopoldo UNISINOS) & $\mathrm{B} 2$ \\
\hline Ciência Florestal (UFSM) & $\mathrm{B} 2$ \\
\hline Desenvolvimento em Questão & $\mathrm{B} 2$ \\
\hline Faces: Revista de Administração (Belo Horizonte. Impresso) & $\mathrm{B} 2$ \\
\hline Floresta (UFPR. Impresso) & B2 \\
\hline Organizações Rurais \& Agroindustriais & $\mathrm{B} 2$ \\
\hline RAI: Revista de Administração e Inovação & $\mathrm{B} 2$ \\
\hline Rama: Revista em Agronegócio e Meio Ambiente & $\mathrm{B} 2$ \\
\hline Revista Ambiente \& Água & $\mathrm{B} 2$ \\
\hline Revista de Administração da UFSM & $\mathrm{B} 2$ \\
\hline
\end{tabular}


QUADRO 1 - Continuação.

\begin{tabular}{|l|c|}
\hline Revista de Ciências da Administração (CAD/UFSC) & B2 \\
\hline Revista de Administração da Unimep & B2 \\
\hline Sociedade \& Natureza (UFU. Online) & B2 \\
\hline Ambiência (Online)/ Ambiência (UNICENTRO) & B3 \\
\hline Desenvolvimento e Meio Ambiente (UFPR) & B3 \\
\hline RACE - Revista de Administração, Contabilidade e Economia & B3 \\
\hline RGSA: Revista de Gestão Social e Ambiental & B3 \\
\hline ReAT - Revista Eletrônica de Administração e Turismo & B3 \\
\hline Reunir: Revista de Administracao, Ciências Contábeis e Sustentabilidade & B3 \\
\hline Revista Brasileira de Administração Científica & B3 \\
\hline Revista Brasileira de Desenvolvimento Regional & B3 \\
\hline Revista Ciências Administrativas (UNIFOR) & B3 \\
\hline Revista Metropolitana de Sustentabilidade & B3 \\
\hline Revista Pensamento Contemporâneo em Administração (UFF) & B3 \\
\hline Revista de Administração IMED & B3 \\
\hline Revista de Gestão Ambiental e Sustentabilidade & B3 \\
\hline Sustentabilidade em Debate & B3 \\
\hline Teoria e Pratica em Administração & B3 \\
\hline
\end{tabular}

Fonte: Dados da pesquisa 2015

Após a seleção dos periódicos, foram realizadas buscas das combinações de termos nos campos título e resumo no sítio eletrônico de cada um e, assim, foram eliminados 9 periódicos, restando 35 apenas que possuíam artigos com os termos pesquisados, sendo encontrados 208 artigos, conforme Quadro 2.

QUADRO 2 - Combinações encontradas

\begin{tabular}{|l|c|}
\hline Termos pesquisados & $\begin{array}{c}\text { Artigos } \\
\text { Encontrados }\end{array}$ \\
\hline sustentabilidade+tecnologia & 17 \\
\hline sustentabilidade+índices & 23 \\
\hline sustentabilidade+agronegócio & 5 \\
\hline sustentabilidade+indicadores & 95 \\
\hline avaliacao+sustentabilidade & 67 \\
\hline organizações+sustentabilidade+agronegócio & 1 \\
\hline Total & $\mathbf{2 0 8}$ \\
\hline
\end{tabular}

Fonte: Dados da pesquisa 2015

A partir dos 208 artigos encontrados, realizouse a leitura de todos os resumos e selecionaram-se 47 artigos. A seleção deu-se a partir da busca de artigos que trabalhassem o tema sustentabilidade na atividade do agronegócio brasileiro.

Após a seleção dos 47 artigos, realizou-se a leitura na íntegra de cada artigo, a partir da qual foi possível realizar a análise qualitativa e quantitativa dos artigos, oportunizando identificar dados sumarizados a respeito do levantamento e também entender as principais ideias e discussões desenvolvidas nos artigos.

Nas análises quantitativas, identificou-se o volume de publicações encontradas, bem como sua classificação no sistema WebQualis da Capes, destacando os principais periódicos que trataram do assunto, evolução anual das publicações, quantidade de autores nos artigos e instituições de ensino em que estão vinculados, bem como os que mais produzem sobre o tema e métodos de pesquisa utilizados nos trabalhos. Também foram realizadas análises qualitativas, considerando as principais conclusões que os artigos selecionados apresentaram e suas contribuições para o campo de estudo.

\section{RESULTADOS E DISCUSSÃO}

Com a leitura de todos os artigos encontrados, foram selecionados os artigos que abordaram o tema central do estudo e com contribuições ao debate, com isso, foram

Organizações Rurais \& Agroindustriais, Lavras, v. 18, n. 4, p. 356-370, 2016 
selecionados 47 artigos distribuídos em 27 revistas de acordo com Quadro 3.

Ao realizar a divisão por estratos foram identificados 5 artigos em revistas com Qualis A2, 4 no estrato B1, 14 no B2 e 24 artigos no B3 representando mais de $50 \%$ dos artigos selecionados. Percebe-se a concentração de artigos nos dois últimos estratos.

Dentre as revistas, destacam-se: Sustentabilidade em Debate, com 7 artigos; RGSA com 5; seguidos de Revista de Administração Pública e RACE com 3 artigos cada. Foram localizados ainda 2 artigos em revistas como:
Sociedade \& Natureza, Revista Árvore, Reunir, Faces, Desenvolvimento em Questão e Ambiência. Os demais 17 artigos estão distribuídos em 17 revistas. Verifica-se, portanto, uma grande distribuição do tema sustentabilidade no agronegócio abordado nas revistas.

No Gráfico 1, demonstra-se a evolução, ao longo dos anos de 2005 a 2015 da abordagem da sustentabilidade no agronegócio e seus indicadores.

Percebe-se que os anos de 2012 e 2014 são os anos com maior quantidade de artigos sobre o tema, verifica-se também que foi, a partir de 2012, que constatou-se uma expressiva

QUADRO 3 - Seleção final dos artigos para análise

\begin{tabular}{|c|c|c|}
\hline Relação revistas (artigos selecionados) & Qualis & Artigos \\
\hline Cadernos EBAPE.BR & A2 & 1 \\
\hline Revista de Administração (FEA-USP) & $\mathrm{A} 2$ & 1 \\
\hline Revista de Administração Pública & $\mathrm{A} 2$ & 3 \\
\hline Ambiente e Sociedade & B1 & 1 \\
\hline REAd. Revista Eletrônica de Administração & B1 & 1 \\
\hline Revista Árvore & B1 & 2 \\
\hline Administração Pública e Gestão Social & B2 & 1 \\
\hline Base & $\mathrm{B} 2$ & 1 \\
\hline Ciência Florestal & $\mathrm{B} 2$ & 1 \\
\hline Desenvolvimento em Questão & $\mathrm{B} 2$ & 2 \\
\hline Faces : Revista de Administração & B2 & 2 \\
\hline Organizações Rurais \& Agroindustriais & $\mathrm{B} 2$ & 1 \\
\hline RAI : Revista de Administração e Inovação & $\mathrm{B} 2$ & 1 \\
\hline Rama : Revista em Agronegócio e Meio Ambiente & $\mathrm{B} 2$ & 1 \\
\hline Revista de administração da Unimep & $\mathrm{B} 2$ & 1 \\
\hline Revista de Ciências da Administração & $\mathrm{B} 2$ & 1 \\
\hline Sociedade \& Natureza & $\mathrm{B} 2$ & 2 \\
\hline Ambiência & B3 & 2 \\
\hline Desenvolvimento e Meio Ambiente (UFPR) & B3 & 1 \\
\hline RACE & B3 & 3 \\
\hline Reunir & B3 & 2 \\
\hline Revista Brasileira de Desenvolvimento Regional & B3 & 1 \\
\hline Revista Ciências Administrativas & B3 & 1 \\
\hline Revista de Gestão Ambiental e Sustentabilidade - GeAS & B3 & 1 \\
\hline Revista Metropolitana de Sustentabilidade & B3 & 1 \\
\hline RGSA: Revista de Gestão Social e Ambiental & B3 & 5 \\
\hline Sustentabilidade em Debate & B3 & 7 \\
\hline Total & & 47 \\
\hline
\end{tabular}

Fonte: Dados da pesquisa 2015 
elevação, quando compara-se seus anos posteriores aos anos anteriores. Apesar do aumento, o debate está longe de se esgotar e constitui, portanto, importante fonte de debates e estudos.

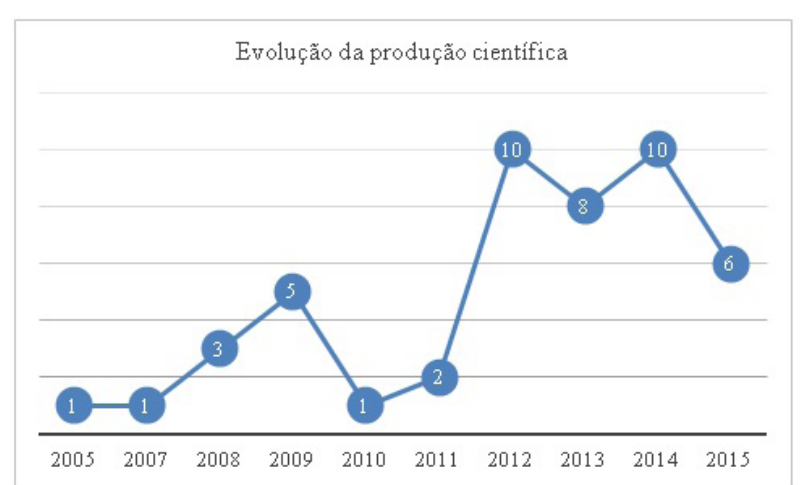

GRÁFICO 1 - Evolução da produção científica Fonte: Dados da pesquisa 2015

É possível, a partir do Gráfico 2, verificar o número de autores responsáveis pelo desenvolvimento dos artigos selecionados.

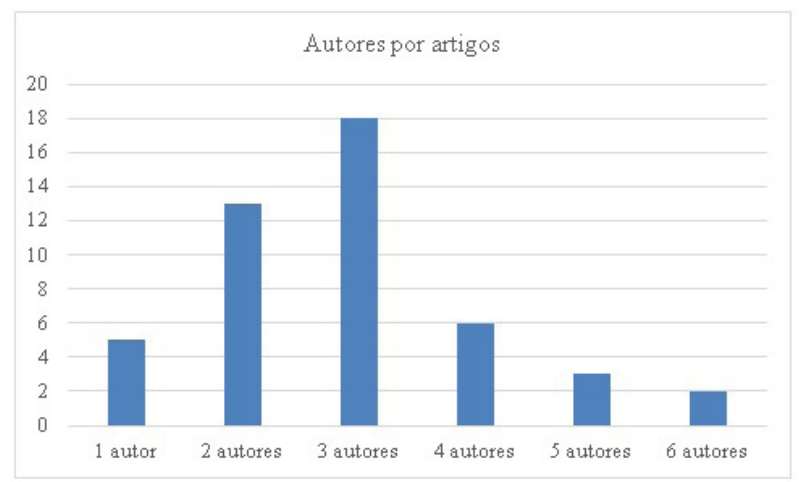

GRÁFICO 2 - Quantidade de autores por artigos Fonte: Dados da pesquisa 2015

A autoria dos artigos vai desde um único autor até a composição máxima de 6 . O maior número de artigos selecionados concentram-se em 3 e 2 autores responsáveis. Dentre tais autores destacam cinco com maior volume de publicações conforme demonstrado no Gráfico 3 .

Totalizaram-se 125 autores responsáveis pelos 47 artigos selecionados, neste estudo, dos quais 5 fizeram mais de um artigo, com destaque para Gesinaldo Ataíde Cândido com participação em 8. Os demais 120 autores contribuíram em apenas um artigo.

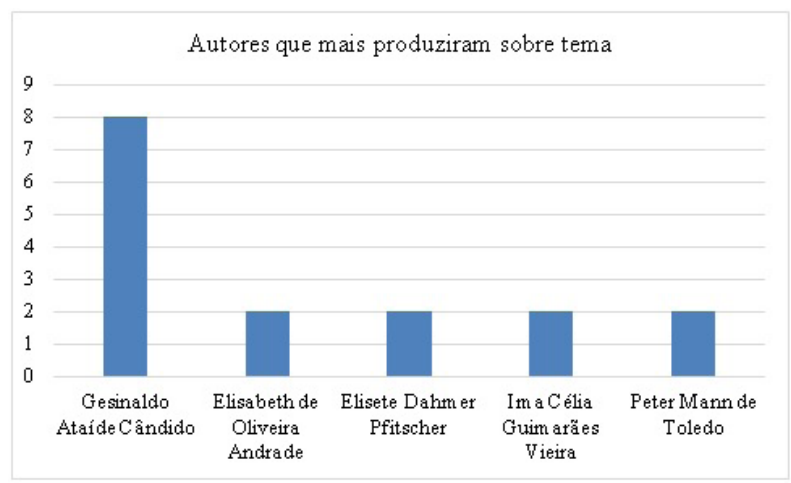

GRÁFICO 3 - Autores que mais produziram sobre o tema Fonte: Dados da pesquisa 2015

No Quadro 4, apresentam-se as instituições dos autores com maior frequência no tema pesquisado.

QUADRO 4 - Ranking das instituições com maior quantidade de autores

\begin{tabular}{|l|c|}
\hline Instituições de Origem dos autores & Quantidade \\
\hline $\begin{array}{l}\text { Universidade Federal de Campina Grande } \\
\text { (UFCG) }\end{array}$ & 17 \\
\hline $\begin{array}{l}\text { Universidade Federal de Santa Catarina } \\
\text { (UFSC) }\end{array}$ & 10 \\
\hline Universidade de São Paulo (USP) & 9 \\
\hline $\begin{array}{l}\text { Universidade Federal de Santa Maria } \\
\text { (UFSM) }\end{array}$ & 6 \\
\hline $\begin{array}{l}\text { Universidade Estadual do Centro-Oeste } \\
\text { (UNICENTRO) }\end{array}$ & 5 \\
\hline Universidade Federal do Pará (UFPA) & 5 \\
\hline Universidade de Brasília (UnB) & 4 \\
\hline Universidade Estadual Paulista (UNESP) & 4 \\
\hline Universidade do Vale do Itajaí (UNIVALI) & \\
\hline
\end{tabular}

Fonte: Dados da pesquisa 2015

Além das 9 instituições mais presentes, foram identificadas as demais 38 instituições com menores frequências dos autores. Foi possível verificar ainda artigos com contribuições de quatro autores de universidades estrangeiras: Universitat de Valencia da Espanha, Universidad Austral de Chile e Instituto Politécnico de Setúbal de Portugal, indicando a presença de parcerias entre universidades nacionais e estrangeiras no debate do tema objeto de estudo. 
Analisou-se também o foco dos artigos selecionados, a partir das palavras-chave relacionadas em cada um. Destacaram-se três principais: sustentabilidade, presente em quase a totalidade dos artigos com 45 menções, indicadores e desenvolvimento com 19 cada. Demonstra-se, portanto, consistência nos debates, mantendo grande relação entre as contribuições dos artigos estudados. Foi possível também identificar o grande debate sobre a sustentabilidade no setor do agronegócio, bem como percebeu-se a necessidade ainda de maior número de estudos sobre essa temática. Dentre os 47 artigos, em 16, os autores apresentam sugestões de novos estudos e abordagens, demonstrando que o tema tem muito a ser debatido e necessita de estudos cada vez mais abrangentes.

No Quadro 5, apresenta-se a distribuição dos artigos quanto aos métodos de pesquisa utilizados. As classificações foram realizadas de acordo com as menções presentes nos próprios artigos pesquisados.

QUADRO 5 - Métodos de pesquisa citados em artigos

\begin{tabular}{|l|c|}
\hline Métodos de pesquisa & Número de citações \\
\hline Fontes Secundárias & 20 \\
\hline Pesquisa bibliográfica & 15 \\
\hline Pesquisa Exploratória & 13 \\
\hline Pesquisa descritiva & 11 \\
\hline Entrevista & 8 \\
\hline Estudo de caso & 6 \\
\hline Questionário & 5 \\
\hline Observação & 4 \\
\hline Análise de Conteúdo & 3 \\
\hline Análise Estatística & 2 \\
\hline Roteiro & 2 \\
\hline Pesquisa Ação & 1 \\
\hline Pesquisa de Campo & 1 \\
\hline Total & $\mathbf{9 1}$ \\
\hline
\end{tabular}

Fonte: Dados da pesquisa 2015

Vale ressaltar que as informações basearam-se no que foi relatado pelos autores dos artigos analisados. A partir disso, é possível constatar que muitos artigos utilizaram mais de um método de pesquisa. Dos 47 artigos analisados, obtiveram-se 13 métodos distintos. O mais presente dos métodos foi o das fontes secundárias citadas em 20 artigos, representando $21,97 \%$ dos artigos, o que demonstra a relevância da utilização de relatórios e documentos para a realização das pesquisas.

Após a quantificação apresentada dos diversos dados relacionados aos artigos selecionados, realizaram-se as leituras de tais artigos para analisar o debate apresentado bem como a relevância das contribuições encontradas nos trabalhos.

Os temas dos artigos estão concentrados principalmente nos debates e elaboração de indicadores e índices para avaliação da sustentabilidade. Lara (2014) realiza um levantamento dos indicadores de sustentabilidade e de responsabilidade social corporativa, afirmando que são os indicadores o meio eficaz para medir o grau de evolução em relação às metas sustentáveis estabelecidas. Entende-se ainda que empresas das diversas atividades econômicas podem adaptar os indicadores de acordo com suas características e necessidades específicas.

Debatendo ainda sobre a relevância dos indicadores de sustentabilidade, Moreira (2013), Carvalho et al. (2011) relacionam diversos indicadores e abordagens como foco no âmbito ambiental. Machado, Lavarda e Lavarda (2011) desenvolveram modelo de avaliação de estratégia ambiental. Enquanto Zuñiga e Habert (2014) abordam a importância dos indicadores socioambientais como ferramenta para medir o desenvolvimento de países, regiões, empresas e setores econômicos.

Guimarães e Feichas (2009) relacionam os desafios da construção dos indicadores e apontam para as suas funções de promover mudanças de comportamento e subsidiar processos de decisão individuais e coletivos para o desenvolvimento sustentável dos setores econômicos, bem como para a sociedade como um todo. Martins e Cândido (2015) complementam com a abordagem da importância da construção de sistemas de sustentabilidade para apoio ao desenvolvimento de políticas públicas que permitam a gestão sustentável dos municípios unida à preocupação com os setores produtivos.

Diversos artigos realizaram a avaliação da sustentabilidade em atividades agropecuárias brasileiras. Souza, Andrade e Cândido (2008) estudaram a sustentabilidade da produção de leite bovino no estado da Paraíba, Magalhães (2014) avaliou se a sustentabilidade da exploração da amêndoa do baru (Dipteryx alata Vogel) - uma espécie do Cerrado brasileiro - realizada por organizações privadas (empresas, cooperativas e associações representativas de agricultores familiares), estabelecidas em municípios goianos e no Distrito Federal, que pode ser caracterizada como uma alternativa sustentável de geração de renda. Machado et al. (2014) realizaram diagnóstico sobre a expansão do 
cultivo da cana- de- açúcar em municípios do estado de São Paulo. Macedo (2013) avaliou o Município de Rio Verde em Goiás sobre sua transformação econômica e seu agronegócio de exportação, e constatou que o município apresenta concentração de capital e exclusão social.

Feitosa, Cândido e Firmo (2010) estudaram a aplicação do método Ecological Footprint Method no município de Campina Grande, na Paraíba, com o objetivo de analisar a sustentabilidade com a mensuração da pressão sobre os recursos naturais, a partir do consumo de energia elétrica, água, geração de resíduos e combustíveis. Observou-se que o metabolismo da cidade requer uma área 449 vezes maior que o seu território para suprir a sua demanda sobre os itens de consumo utilizados.

Vasconcelos, Andrade e Cândido (2009) avaliaram o cultivo de mamona na Bahia, enquanto Formiga Junior, Cândido e Amaral (2015) o cultivo de melão. Em contrapartida, Souza, Mann e Melo (2014) abordaram a conservação da árvore Erythrina velutina Willd, popularmente conhecida como corticeira-do-banhado, mulungu ou suinã.

Os autores Ramos, Santos e Almeida Neto (2015) debatem o agronegócio no oeste baiano. Gardini, Azevedo e Matias (2014) desenvolveram um estudo sobre as práticas e programas sustentáveis na bovinocultura de corte no Mato Grosso do Sul.

O extrativismo também foi abordado por Nogueira, Nascimento Junior e Bastos (2009), bem como foi realizada a análise da sustentabilidade da cadeia produtiva de produtos florestais não-madeiráveis em Minas Gerais por Siena, Muller e Fachinello (2012). No mesmo estado, Coelho et al. (2008) realizaram estudo sobre o manejo das áreas florestais indicando nível de exploração acima do limite máximo de intervenção permitido por lei.

O debate também englobou a sustentabilidade em cooperativas, como a de fruticultores de Abaetetuba no estado do Pará abordada por Silva, Barbosa e Albuquerque (2013) e o projeto de hortifrutigranjeiros da Coopesperança (Cooperativa Mista dos Pequenos Produtores Rurais e Urbanos Vinculados ao Projeto Esperança), que desenvolve grupos organizados para comercializar de forma direta os produtos dos empreendimentos solidários, no campo e na cidade, desenvolvido juntamente com o Banco da Esperança da Arquidiocese de Santa Maria e da Cáritas RS analisado por Ende et al. (2012). Enquanto Carvalho e Rios (2007) avaliaram a associação de produtores rurais de Águas Belas em Pernambuco, a partir do qual constataram-se muitos benefícios bem como a necessidade de profissionalização da administração da Associação.
Além disso, Rossetto et al. (2008) realizaram a análise socioambiental de municípios de Santa Catarina, enquanto Cardoso, Toledo e Vieira (2014) avaliaram a gestão ambiental no município de Moju, no estado do Pará. Oliveira, Oliveira e Carniello (2015) aplicaram a ferramenta barômetro da sustentabilidade no município de Taubaté, em São Paulo e Amorim, Araújo e Cândido (2014) no semiárido do nordeste brasileiro.

Guimarães e Peixoto (2015) e Vital et al. (2009) relacionam a importância dos índices da sustentabilidade no desempenho das mais diversas atividades econômicas e o impacto financeiro gerado. Sob a ótica das empresas no aspecto geral, englobando agronegócio e demais setores econômicos, foram analisados dois estudos que apresentam resultados distintos. Nunes et al. (2012) afirmam que não existem diferenças entre os indicadores contábeis dos empreendimentos considerados sustentáveis ou não, contradizendo o estudo de Macedo, Corrar e Siqueira (2012) que aponta: as empresas socioambientalmente responsáveis tem desempenho contábil-financeiro melhor.

Kneipp et al. (2013) estudaram o nível da divulgação das informações de sustentabilidade nos relatórios de empresas brasileiras. As organizações estudadas possuíam representantes dos setores de energia, produtos florestais e papel, por exemplo. Constatou-se que não são divulgadas todas as informações necessárias, os relatórios são incompletos, muitos indicadores de sustentabilidade não são relatados. Os autores sugerem ainda que podem ser realizados estudos com empresas das mais variadas atividades econômicas, sendo possível a avaliação de empresas relacionadas à agricultura e pecuária, por exemplo.

Beato, Souza e Parisotto (2009), por sua vez, estudaram a rentabilidade dos índices de sustentabilidade na Bolsa de Valores de São Paulo, e constataram que a rentabilidade dos índices que consideram os aspectos socioambientais é maior do que os índices que não os levam em conta. Empresas do agronegócio, por exemplo, poderiam aderir a tais índices para conquistar investidores que buscam mais do que rentabilidade e dividendos, valorizam empresas com práticas socioambientais e governança corporativa.

Costa e Bueno (2012) avaliaram a eficiência energética e econômica na produção de leite bovino, que apresentaram índices favoráveis, mas sob a ótica da sustentabilidade do agroecossistema, verifica-se a necessidade de buscar alternativas produtivas mais sustentáveis dos pontos de vista energético e econômico, com utilização mais racional dos recursos disponíveis. 
Silveira e Pfitscher (2012) analisam a sustentabilidade e debatem o aspecto ambiental na geração e distribuição de energia elétrica, verificando-se desempenho ambiental alto com valorização do meio ambiente e prevenção da poluição. Parente (2014) confirma tal afirmação, a partir do resultado obtido em seu estudo que demonstra que o setor de energia elétrica desenvolve práticas isofórmicas nas dimensões econômica, ambiental e social. Melo e Caldana (2014) entendem que o setor de energia tem apresentado evolução nos indicadores de sustentabilidade, bem como na sua comunicação. Com estudo de Borges (2012), no Pará, constatou-se a maior relevância do aspecto econômico na análise do insumo elétrico utilizado para o desenvolvimento de atividades econômicas como o agronegócio, por exemplo.

A discussão sobre o desenvolvimento sustentável tem sido crescente. Lourenço e Carvalho (2013) desenvolveram uma pesquisa bibliográfica, e a partir de então, identificaram importantes lacunas, pois verificaram a maior concentração de discussões da sustentabilidade ambiental, e para eles é necessário o debate nos aspectos sociais e econômicos também, trabalhando as três dimensões da sustentabilidade de forma igual. Luiz et al. (2013) analisaram a aplicação da agenda ambiental na administração pública e da legislação ambiental nas atividades socioambientais praticadas por um Instituto Federal de Educação e constataram poucas ações de conscientização sobre o uso racional dos recursos naturais e gestão dos resíduos gerados.

Silva, Souza e Leal (2012) estudaram o município de Formosa em Goiás, a partir da elaboração de indicadores que permitiram a mensuração da exclusão social, da segregação social e ambiental.

Diversos estudos foram desenvolvidos a partir da elaboração e aplicação de instrumentos para mensuração dos indicadores da sustentabilidade em atividades agrícolas e pecuárias nas mais variadas regiões do país.

No Pará, o polo do dendê, composto por 26 municípios, foram avaliados 7 municípios com a aplicação do instrumento barômetro da sustentabilidade, avaliando os diversos aspectos da sustentabilidade, e foi possível perceber que existem níveis de desenvolvimento diferenciados entre eles, mas verifica-se a baixa diversificação econômica. Além disso, aquela região apresenta graves problemas socioambientais (LAMEIRA; VIEIRA; TOLEDO, 2015).

Em um assentamento de Mossoró, no estado do Rio Grande do Norte, onde a fruticultura irrigada é presente, realizou-se a aplicação da metodologia MESMIS (Marco para Avaliação de Sistemas de Manejo de Recursos
Naturais Incorporando Indicadores de Sustentabilidade) que é um sistema de indicadores voltados para a agricultura, a partir do qual foram identificados diversos pontos críticos, como: água, solo, dependência de insumos externos, qualidade de vida e o rendimento. Enquanto existem muitas potencialidades a ser exploradas, entre elas: a assistência técnica e crédito rural (FORMIGA JUNIOR; CÂNDIDO; AMARAL, 2015).

Constatou-se que a região oeste da Bahia possui diversos problemas de cunho social, ambiental e econômico e as associações do agronegócio pouco fazem para mudar esta realidade, com poucas iniciativas, das quais nenhuma engloba as três dimensões da sustentabilidade plenamente. Verifica-se, portanto, a necessidade de diálogo entre os diversos agentes sociais para formação de parcerias que permitam que as ações proporcionem benefícios à maior quantidade possível de grupos (RAMOS; SANTOS; ALMEIDA NETO, 2015).

Ainda no estado da Bahia, a cultura da produção da mamona constitui importante fonte de renda, no entanto, constatou-se a insustentabilidade da microrregião de Irecê nos aspectos: social, econômico, ambiental e institucional. Entende-se como importante a implementação de políticas para investimentos em fatores sociais, com a melhoria da saúde e educação, e preservação dos recursos naturais, a partir da recuperação de áreas degradadas (VASCONCELOS; ANDRADE; CÂNDIDO, 2009).

Com as crescentes preocupações ambientais, a agricultura familiar tem na agroecologia grande expectativa de sustentabilidade. Em associação de produtores de Lagoa Seca, na Paraíba, avaliaram-se diversos indicadores da sustentabilidade com níveis satisfatórios na agricultura familiar desenvolvida. No entanto, existe a necessidade de políticas eficientes que fortaleçam a atividade, já que existem muitos desafios como alto custo de recuperação do solo e certificação, além da falta de linhas de créditos específicas e assistência técnica. Contitui-se fundamental, portanto, a união entre os agricultores, sociedade e o poder público (SANTOS; CÂNDIDO, 2013).

Corrobou-se a necessidade de ações por parte do poder público e dos próprios agricultores, ao avaliar-se a agricultura familiar dentro do agronegócio no município de Ceará Mirim - RN, com a aplicação de indicadores de sustentabilidade das explorações agrícolas. Verificou-se que o cultivo orgânico, dentre as culturas é o que apresenta nível maior de sustentabilidade, com maior equilíbrio entre as diversas dimensões (MELO; CÂNDIDO, 2013).

$\mathrm{Na}$ região centro-oeste brasileira, percebe-se o dinamismo econômico, principalmente no agronegócio. $\mathrm{O}$ 
município de Rio Verde em Goiás, apresenta características comuns em muitos municípios brasileiros, com um crescimento econômico bastante elevado, no entanto, discute-se as questões relacionadas às transformações ocorridas no espaço. O agronegócio, tem apresentado como ponto negativo, processo de acumulação de riquezas, acarretando aumento de segregação socioespacial; elevação do custo de vida e aumento do déficit habitacional (MACEDO, 2013).

A pecuária também constitui atividade muito presente no país. Foi analisado a sustentabilidade nas mais diversas dimensões dos produtores de leite do agreste paraibano. Verificou-se a insustentabilidade. Identificouse a precariedade da infraestrutura de saneamento básico, acarretando problemas de saúde. Tem-se, no entanto, desenvolvido a questão social a partir de ações na educação e saúde. Economicamente, todos os indicadores apresentaram resultados negativos, indicando baixo nível de desenvolvimento e a necessidade de ações e programas eficientes (SOUZA; ANDRADE; CÂNDIDO, 2008).

$\mathrm{Na}$ bovinocultura de corte em Mato Grosso do Sul, são desenvolvidos programas sustentáveis, com ganhos ambientais e de competitividade no mercado. Ações como a redução do desmatamento sobre a floresta e diversificação dos métodos de produção têm permitido a melhoria dos índices de produtividade. Muitas das contribuições ocorrem, devido as parcerias entre organizações não governamentais e instituições de pesquisa, com desenvolvimento de novas técnicas e modelos de produção sustentáveis, evitando os aspectos negativos (GARDINI; AZEVEDO; MATIAS, 2014).

Os biocombustíveis têm apresentado cada vez maior destaque para suprimento energético. $\mathrm{O}$ cultivo de cana-de-açúcar possibilita a produção de bioetanol. No entanto, a partir da aplicação do barômetro da sustentabilidade em algumas cidades produtores de São Paulo, percebe-se impacto negativo do cana-de-açúcar sobre bem-estar ecossistêmico (MACHADO et al., 2014).

A cana-de-açúcar tem apresentado evolução no Brasil, decorrente, em grande parte, das políticas públicas de incentivo à produção de álcool como fonte alternativa ao pétroleo. No município de Carmo do Rio Verde, em Goiás, identificou-se o perfil sustentável nas dimensões social, econômica, ambiental e institucional. No entanto, entre 2005 e 2010 , verificou-se queda considerável no quesito desenvolvimento sustentável, demonstrando despreocupação com a sustentabilidade, haja vista a diminuição de todos os índices analisados. Permite-se entender que a expansão da cana-de-açúcar afeta o município, e não existem políticas públicas adequadas a esse cenário (RODRIGUES; NAJBERG, 2012).
Uma das atividades econômicas defendidas por ambientalistas e apresentada como alternativa de sustentabilidade é o extrativismo. No entanto, após a análise do mercado para quatro produtos: buriti, fava d'anta, baru e pequi, entende-se a necessidade de cautela nesta ideia. São necessárias medidas efetivas de apoio que permitam, de fato, a existência de uma atividade econômica que permita renda sustentada para os dependentes desse sustento (NOGUEIRA; NASCIMENTO JUNIOR; BASTOS, 2009).

Freitas et al. (2012) debateram a transferência de tecnologia da universidade para a sociedade, embasada em fatores de sustentabilidade, com vistas ao desenvolvimento regional sustentável em uma análise do projeto permanente de extensão "Apiários Rio de Mel" junto às unidades de agricultura familiar da região Centro-Sul do Paraná, e sua importância para a sustentabilidade regional.

Entende-se, portanto, fundamental a discussão de como desenvolver-se com a aplicação efetiva do conceito de sustentabilidade nos mais diversos aspectos. Os indicadores desenvolvidos são ferramentas importantes que possibilitam a mensuração, bem como a compreensão das necessidades encontradas e identificação das ações indicadas para tais situações (ZUÑIGA; HABERT, 2014).

Silva e Drummond (2005) apontam para a importância das certificações socioambientais para o desenvolvimento de atividades agropecuárias em geral, como a extrativista. Os autores analisaram o setor mineiro da Amazônia, a partir de indicadores, e foi constatado destaque para o aspecto ambiental.

A partir do debate dos artigos analisados, verificouse a necessidade de melhoria nas práticas sustentáveis do agronegócio nacional bem como da elaboração de políticas públicas que incentivem o melhor aproveitamento de recursos visando ao desenvolvimento sustentável e saudável das atividades econômicas, entre elas, o agronegócio.

\section{CONSIDERAÇÕES FINAIS}

Com análise dos artigos selecionados, verificou-se o debate crescente da sustentabilidade no setor do agronegócio em suas diversas atividades e nas mais variadas regiões brasileiras. Foi possível ainda constatar a diversidade de culturas presentes no país.

No entanto, o foco de preocupação dos autores tem se concentrado na mensuração da sustentabilidade a partir da elaboração e aplicação de indicadores nas atividades agropecuárias brasileiras, haja vista, que os indicadores permitem a visualização real e válida da realidade

Organizações Rurais \& Agroindustriais, Lavras, v. 18, n. 4, p. 356-370, 2016 
encontrada, constituindo a forma mais efetiva de alertar e permitir desenvolvimento de políticas públicas.

Apesar dos diversos avanços, notou-se a insustentabilidade ainda muito presente no agronegócio nacional, a falta de políticas públicas adequadas e incentivos aos produtores com práticas sustentáveis.

As perspectivas futuras são positivas, tende-se ao crescimento dessas práticas, em decorrência da conscientização e a crescente preocupação da sociedade com seu futuro, o que acarreta em consumidores cada vez mais atentos e exigentes de produtos com qualidade e ecologicamente corretos.

Perceberam-se diversas possibilidades de estudos futuros como o desenvolvimento de indicadores com maior número de variáveis, além da avaliação de atividades nos mais variados setores econômicos. Pode-se ainda, desenvolver estudos comparativos entre atividades, regiões e períodos. Seria interessante também analisar as políticas públicas no seu discurso e prática, bem como debater sobre a evolução da legislação competente. Verifica-se, portanto, que o tema está longe de encerrar o seu debate.

\section{REFERÊNCIAS}

AMORIM, A. de S.; ARAÚJO, M. F. F.; CÂNDIDO, G. A. Uso do barômetro da sustentabilidade para avaliação de um município localizado em região semiárida do nordeste brasileiro. Desenvolvimento em Questão, Ijuí, ano 12, n. 25, p. 189-217, jan./mar. 2014.

ASSAD, E. D.; MARTINS, S. C.; PINTO, H. P. Sustentabilidade no agronegócio brasileiro. Rio de Janeiro: Fundação Brasileira para o Desenvolvimento Sustentável, 2012.

BAtista, I. H.; AlBuQuerque, C. C. de. Desenvolvimento sustentável: novos rumos para a humanidade. Revista Eletrônica Aboré, Manaus, 3. ed. 2007.

BEATO, R. S.; SOUZA, M. T. S. de; PARISOTTO, I. R. dos S. Rentabilidade dos índices de sustentabilidade empresarial em bolsas de valores: um estudo do ISE/ BOVESPA. Revista de Administração e Inovação, São Paulo, v. 6, n. 3, p. 108-127, set./dez. 2009.

BORGES, F. Q. Administração pública do setor elétrico: indicadores de sustentabilidade no ambiente residencial do estado do Pará (2001-10). Revista de Administração
Pública, Rio de Janeiro, v. 46, n. 3, p. 737-751, maio/ jun. 2012.

CARdoso, A. S.; TOLEDO, P. M. de; VIEIRA, I. C. G. Dimensão institucional da sustentabilidade e gestão ambiental no município de Moju, Pará: uma aplicação do barômetro da sustentabilidade. Sustentabilidade em Debate, Brasília, v. 5, n. 1, p. 117-135, jan/abr. 2014.

CARVALHO, D. M. de; RIOS, G. S. L. Participação, viabilidade e sustentabilidade: dimensões de desenvolvimento local numa associação de produtores rurais. Organizações Rurais \& Agroindustriais, Lavras, v. 9, n. 3, p. 402-420, 2007.

CARVALHO, J. R. M. de; et al. Proposta e validação de indicadores hidroambientais para bacias hidrográficas: estudo de caso na sub-bacia do alto curso do Rio Paraíba, PB. Sociedade \& Natureza, Uberlândia, ano 23, n. 2, p. 295-310, maio/ago. 2011.

CENTRODEESTUDOSAVANÇADOS EM ECONOMIA APLICADA - CEPEA. PIB Agro CEPEA-USP/CNA. Disponível em: $<$ http://cepea.esalq.usp.br/pib/>. Acesso em 20 out. 2015.

COELHO, D. J. da S. et al. Análise documental e de consistência técnica de planos de manejo florestal em áreas de formações florestais, no estado de Minas Gerais. Revista Árvore, Viçosa, v.32, n.1, p. 69-80, 2008.

CONTINI, E. et al. Evolução recente e tendências do agronegócio. Revista de política agrícola, Brasília, Jan./ Fev./Mar. 2006.

COSTA, Z. da F.; BUENO, O. de C. Análise das eficiências energética e econômica de dois diferentes sistemas de produção de leite bovino em explorações familiares. Ambiência, Guarapuava, v.8, n.2, p. 361-375, maio/ ago. 2012.

DIAS, R. Gestão ambiental: responsabilidade social e sustentabilidade. São Paulo: Atlas, 2011.

ELKINGTON, J. Enter the Triple Bottom Line. In: A. Henriques \& J. Richardson (Eds.). The Triple Bottom Line: Does it All Add Up? Assessing the Sustainability of Business and CSR. London: Earthscan Publications, 2004. 
ENDE, M. V. et al. Índices de sustentabilidade de projetos da economia solidária: o caso esperança/ coopesperança. Revista de Gestão Social e Ambiental, São Paulo, v. 6, n. 3, p. 47-63, set./dez. 2012.

FEITOSA, M. J. da S.; CÂNDIDO, G. A.; FIRMO, L. A. Sistemas de indicadores de sustentabilidade: uma aplicação do ecological footprint method no município de Campina Grande (PB). Ambiência, Guarapuava, v.6, n.3, p. 393-414, set./dez. 2010.

FORMIGA JÚNIOR, I. M.; CÂNDIDO, G. A.; AMARAL, V. S. do. O cultivo de melão no assentamento São Romão em Mossoró/RN: determinação dos indicadores de sustentabilidade através da metodologia MESMIS. Sustentabilidade em Debate, Brasília, v. 6, n. 1, p. 7085, jan/abr. 2015.

FREITAS, C. C. G. et al. Transferência tecnológica e inovação por meio da Sustentabilidade. Revista de Administração Pública, Rio de Janeiro, v. 46, n. 2, p. 363-84, mar./abr. 2012.

GARDINI, A. de O.; AZEVEDO, D. B. de; MATIAS, M. J. de A. Programas e práticas sustentáveis na bovinocultura de corte de Mato Grosso do Sul: caminhos para a consolidação de uma bovinocultura sustentável. Revista de Administração, Contabilidade e Sustentabilidade, Campina Grande, v.4, n. 1, p. 1-18, 2014.

GAZZONI, D. L. A sustentabilidade da soja no contexto do agronegócio brasileiro e mundial. Londrina: Embrapa Soja, 2013.

GIL, A. C. Como elaborar projetos de pesquisa. 4.ed. São Paulo: Atlas, 2002.

GUIMARÃES, R. P.; FEICHAS, S. A. Q. Desafios na Construção de Indicadores de Sustentabilidade. Ambiente \& Sociedade, Campinas, v. 12, n. 2, p. 307-323, jul./dez. 2009.

GUIMARÃES, T. M.; PEIXOTO, F. M. Acompensação dos gestores, a sustentabilidade empresarial e a performance das empresas brasileiras. Revista de Administração da UNIMEP, Piracicaba, v.13, n.2, p. 186-212, maio/ago. 2015.

KNEIPP, J. M. et al. Gestão para a sustentabilidade em empresas do setor mineral. Revista de Ciências de
Administração, Florianópolis, v. 14, n. 33, p. 52-67, 2012.

KNEIPP, J. M. et al. Características determinantes no nível de divulgação de informação em relatórios de sustentabilidade de empresas brasileiras. Race, Joaçaba, v. 12, n. 2, p. 295-338, jul./dez. 2013

LAMEIRA, W. J. de M.; VIEIRA, I. C. G.; TOLEDO, P. M. de. Panorama da sustentabilidade na fronteira agrícola de bioenergia na Amazônia. Sustentabilidade em Debate, Brasília, v. 6, n. 2, p. 193-210, mai/ago. 2015.

LARA, F. F. de. Análise bibliográfica dos indicadores de sustentabilidade e de responsabilidade social corporativa. Revista Metropolitana de Sustentabilidade, São Paulo, v. 4, n. 3, p. 67-86, set./dez. 2014.

LOURENÇO, M. L.; CARVALHO, D. Sustentabilidade social e desenvolvimento sustentável. Race, Joaçaba, v. 12, n. 1, p. 9-38, jan./jun. 2013.

LUIZ, L. C. et al. Agenda ambiental na administração aública (A3P) e práticas de sustentabilidade: estudo aplicado em um Instituto Federal de Educação, Ciência e Tecnologia. Administração Pública e Gestão Social, Viçosa, v. 5, n. 2, p. 114-134, abr./jun. 2013.

MACEDO, M. A. da S.; CORRAR, L. J.; SIQUEIRA, J. R. M. de. Análise comparativa do desempenho contábilfinanceiro de empresas socioambientalmente responsáveis no Brasil. Revista de Administração e Contabilidade da Unisinos, São Leopoldo, v. 9, n. 1, p. 13-26, jan./mar. 2012.

MACEDO, F. C. de. Transformação econômica, inserção externa e dinâmica territorial no Centro-Oeste brasileiro: o caso de Rio Verde. Sociedade \& Natureza, Uberlândia, v. 25, n. 1, p. 35-50, jan/abr. 2013.

MACHADO, D. G.; LAVARDA, R. A. B.; LAVARDA, C. E. F. Modelo de avaliação de estratégia ambiental. Faces: Revista de Administração, Belo Horizonte, v. 10, n. 3, p. 32-51, jul./set. 2011 .

MACHADO, P. G. et al. Diagnóstico da expansão da cana-deaçúcar: aplicação do barômetro da sustentabilidade nos municípios de Barretos e Jaboticabal (SP). Sustentabilidade em Debate, Brasília, v. 5, n. 1, p. 1328, jan./abr. 2014.

Organizações Rurais \& Agroindustriais, Lavras, v. 18, n. 4, p. 356-370, 2016 
MAGALHÃES, R. M. A cadeia produtiva da amêndoa do baru (dipteryx alata vog.) no cerrado: uma análise da sustentabilidade da sua exploração. Ciência Florestal, Santa Maria, v. 24, n. 3, p. 665-676, jul.-set. 2014.

MAIA, M. R. Sustentabilidade e agricultura familiar em Vitória da Conquista - BA. 2012. 287 f. Tese (Doutorado em Geografia) -Programa de Pós graduação em Geografia, Universidade Federal do Sergipe, São Cristovão - SE, 2012.

MARTINS, M. de F.; CÂNDIDO, G. A. Sistemas de indicadores de sustentabilidade urbana: os desafios do processo de mensuração, análise e monitoramento. Sustentabilidade em Debate, Brasília, v. 6, n. 2, p. 138154, maio/ago. 2015.

MELO, L. E. L. de; CÂNDIDO, G. A. O Uso do Método IDEA na Avaliação de sustentabilidade da agricultura familiar no município de Ceará Mirim - RN. Revista de Administração, Contabilidade e Sustentabilidade, Campina Grande, v. 3, n. 2, p. 1-19, mai./ago. 2013.

MELO, M. S. de; CALDANA, A. C. F. Relatório de sustentabilidade no Brasil: análise de sua utilização nos setores serviços financeiros e energia. Sustentabilidade em Debate, Brasília, v. 5, n. 1, p. 29-50, jan./abr. 2014.

MOREIRA, S. B. Sobre a medição da componente ambiental do desenvolvimento: principais abordagens e indicadores. Desenvolvimento e Meio Ambiente, Curitiba, v. 27, p. 121-132, jan./jun. 2013.

NOGUEIRA, J. M.; NASCIMENTO JUNIOR, A.; BASTOS, L. Empreendimentos extrativistas como alternativas para geração de renda: do sonho ambientalista à realidade do estudo de mercado. Revista Ciências Administrativas, Fortaleza, v. 15, n. 1, p. 85-104, jan./ jun. 2009.

NOVAES, A. L. et al. Análise dos fatores críticos de sucesso do agronegócio brasileiro. In: CONGRESSO SOCIEDADE BRASILEIRA DE ECONOMIA, ADMINISTRAÇÃO E SOCIOLOGIA RURAL, 48., 2009, Campo Grande, MS. Anais...Campo Grande: SOBER, 2009.

NUNES, T. C. S. et al. Are sustainable companies less risky and more profitable? Revista de Administração, São Paulo, v.47, n.3, p.422-435, jul./ago./set. 2012
OLIVEIRA, E. L. de; OLIVEIRA, E. A. de A. Q.; CARNIELLO, M. F. O Barômetro da Sustentabilidade aplicado ao município de Taubaté-SP. Desenvolvimento em Questão, Ijuí, ano 13, n. 30, p. 230-264, abr./jun. 2015.

PARENTE, P. H. N. et al. Teoria institucional e disclosure de sustentabilidade: uma investigação no setor de energia elétrica. Race, Joaçaba, v. 13, n. 3, p. 889-918, set./dez. 2014.

PORTO, M. F.; MILANEZ, B. Eixos de desenvolvimento econômico e geração de conflitos socioambientais no Brasil: desafios para a sustentabilidade e a justiça ambiental. Ciência \& Saúde Coletiva, Rio de Janeiro, v. 14, n. 6, p. 1983-1994. 2009.

RAMOS, J. R. N. de S.; SANTOS, F. da S.; ALMEIDA NETO, P. P. de. Limitações na responsabilidade socioambiental no agronegócio do oeste baiano. Revista de Gestão Ambiental e Sustentabilidade, v. 4, n. 1, p. 30-45, jan./abr. 2015.

RODRIGUES, D. M.; NAJBERG, E. Indicadores de sustentabilidade das políticas públicas decorrentes da expansão do setor sucroalcooleiro em Carmo do Rio Verde (GO). Revista de Gestão Social e Ambiental, São Paulo, v. 6, n. 3, p. 64-80, set./dez. 2012.

ROSSETTO, A. M. et al. Avaliação integrada de indicadores socioambientais em municípios catarinenses. Faces: Revista de Administração, Belo Horizonte, v. 7, n. 3, p. 81-104, jul./set. 2008.

SACHS, I. Desenvolvimento: includente, sustentável, sustentado. Rio de Janeiro: Garamond, 2008.

SANTOS, J. G.; CÂNDIDO, G. A. Sustentabilidade e agricultura familiar: um estudo de caso em uma associação de agricultores rurais. Revista de Gestão Social e Ambiental, São Paulo, v. 7, n. 1, p. 70-86, jan./ abr. 2013.

SIENA, O.; MULLER, C. A. da S.; FACHINELLO, D. T. Visões de sustentabilidade dos atores da cadeia produtiva dos produtos florestais não-madeiráveis. Revista de Gestão Social e Ambiental, São Paulo, v. 6, n. 1, p. 5369, jan./abril 2012. 
SILVA,A. R. P.; BARBOSA, M. J. de S.; ALBUQUERQUE, F. dos S. Sustentabilidade de empreendimentos econômicos solidários: análise da Cooperativa dos Fruticultores de Abaetetuba. Revista de Administração Pública, Rio de Janeiro, v. 47, n. 5, p. 1189-1211, set./out. 2013.

SILVA, A. S. da; SOUZA, J. G. de; LEAL, A. C. Qualidade de vida e meio ambiente: experiência de consolidação de indicadores de sustentabilidade em espaço urbano. Sustentabilidade em Debate, Brasília, v. 3, n. 2, p. 177 196, jul./dez. 2012.

SILVA, D. B. da. Sustentabilidade no agronegócio: dimensões econômica, social e ambiental. Comunicação \& Mercado/UNIGRAN, Dourados, v. 1, n. 3, p. 23-34, jul-dez. 2012.

SILVA, M. A. R. da; DRUMMOND, J. A. Certificações socioambientais: desenvolvimento sustentável e competitividade da indústria mineira na Amazônia. Cadernos Ebape.BR, Rio de Janeiro, p. 1-21, 2005.

SILVEIRA, M. L. G. da; PFITSCHER, E. D. Sustentabilidade ambiental analisada da parte de uma empresa do setor elétrico. Revista em Agronegócios e Meio Ambiente, Maringá, v.5, n.1, p. 163-189, jan./abr. 2012.

SOUZA, D. C. L.; MANN, R. S.; MELO, M. F. de V. Indicadores de sustentabilidade para conservação genética de erythrina velutina willd., em área de mata ciliar. Revista Árvore, Viçosa, v.38, n.6, p.1103-1113, 2014.

SOUZA, E. G. de; ANDRADE, E. de O.; CÂNDIDO, G. A. A aplicação das dimensões do desenvolvimento sustentável: um estudo exploratório nos municípios produtores de leite bovino no estado da Paraíba. Read, Porto Alegre, v. 14, n. 3, p. 650-669, set/dez. 2008.
SOUZA, T. A.; VERÍSSIMO, M. P. O papel das commodities para o desempenho exportador brasileiro. Revista Indicadores Econômicos FEE, Porto Alegre, v. 40, n. 2, p. 79-94, 2013.

TORRES, D. A. P. et al. Viabilidade econômica da produção agropecuária no Brasil: aspectos gerais, metodologia e principais resultados. In: CAMPOS, S. K. et al. (orgs). Sustentabilidade e sustentação da produção de alimentos no Brasil: o desafio da rentabilidade na produção. v. 2. Brasília: CGEE, 2014.

VASCONCELOS, A. C. F. de; ANDRADE, E. de O.; CÂNDIDO, G. A. Indicadores de sustentabilidade e suas influências no desenvolvimento local: uma aplicação em região produtora de mamona no estado da Bahia. Revista de Gestão Social e Ambiental, São Paulo, v. 3, n. 1, p. 105-120, Jan./Abr. 2009.

VITAL, J. T. et al. A influência da participação no índice de sustentabilidade empresarial (ISE) no desempenho financeiro das empresas. Revista de Ciências da Administração, Florianópolis, v. 11, n. 24, p. 11-40, maio/ago. 2009.

ZUÑIGA, C. H.; HABERT, G. P. ¿Estamos como estamos porque somos como somos? Importancia de los indicadores socio-ambientales para um desarrollo a escala humana. Revista Brasileira de Desenvolvimento Regional, Blumenau, v. 2, n. 2, p. 27-46, primavera 2014.

VILHA, A. M.; CARVALHO, R. de Q. Desenvolvimento de novas competências e práticas de gestão da inovação voltadas para o desenvolvimento sustentável: estudo exploratório da Natura. Cad. EBAPE.BR, Rio de Janeiro, v. 3, n. spe, p. 01-15, 2005. 